\title{
УПРАВЛЕНИЕ РАЗВИТИЕМ ОТРАСЛИ ТУРИЗМА В КОНТЕКСТЕ УСТОЙЧИВОГО РАЗВИТИЯ ЭКОНОМИКИ
}

\author{
(c) 2021 Родионов Дмитрий Григорьевич \\ доктор экономических наук, профессор, Высшая инженерно-экономическая школа \\ Санкт-Петербургский политехнический университет Петра Великого, Россия, Санкт-Петербург \\ E-mail: dmitry.rodionov@spbstu.ru \\ (c) 2021 Лобанова Полина Игоревна \\ студент, Высшая инженерно-экономическая школа \\ Санкт-Петербургский политехнический университет Петра Великого,, Россия, Санкт-Петербург \\ E-mail: lobanova.pi@edu.spbstu.ru
}

\section{(c) 2021 Конников Евгений Александрович}

кандидат экономических наук, доцент, Высшая инженерно-экономическая школа Санкт-Петербургский политехнический университет Петра Великого, Россия, Санкт-Петербург

E-mail: konnikov.evgeniy@gmail.com

Туризм оказывает значимое воздействие на хозяйство страны, а экономики некоторых стран полностью определяются успешностью данной отрасли. Благодаря правильному развитию туризма, страна может не только увеличить свой ВВП, но и повысить качество жизни граждан. Целью данной работы являлось решение по поднятию уровня туристической привлекательности в контексте экономического развития страны. Чтобы достичь результатов, были изучены такие показатели, как экономическая свобода, процветание страны, капиталовложения в туризм, поиск достопримечательностей в Интернете, и их влияние на туризм. Также были изучены связи между данными показателями и метадинамика, которая влияла на эти связи и оказывала свое воздействие на модель в целом. В данной работе были определены виды зависимостей и временные лаги; с помощью применения парной и множественной регрессий, были найдены коэффициенты детерминации, р-значения, ошибки аппроксимации, остатки, факторы вздутия дисперсии, коэффициенты эластичности и предсказанные зависимые переменные. На основе получившихся данных делались выводы о связях, исследовалась метадинамика и предлагалось решение по управлению связями. По результатам проведенного анализа была получена концептуальная модель, в которой подтвердилась зависимость турпотока от уровня процветания страны, информационной составляющей в Интернете и суммы инвестиций в туризм, а также связь между индексом экономической свободы и индексом процветания страны. Повышая экономическую свободу в стране, развивается сама страна, что положительно влияет на турпоток. Зависимость капиталовложений от количества туристов существовала только до определенного года, а связь между капиталовложениями в туризм и интересом людей к стране при правильном информационном распространении в скором времени должна появиться. В результате было заключено, что максимальный эффект получают страны, которые учитывают свои особенности, развивают их и правильно преподносят. Было выявлено, что качественное развитие отрасли возможно только параллельно с развитием всего государства.

Ключевые слова: туризм, инвестиции, капиталовложения, инновации, процветание, поиск в Интернете, экономическая свобода, турпоток, достопримечательности.

Проблема определения влияния внешней среды на туризм является актуальной потому, что туризм может играть определяющую роль для экономик разных стран. Можно, действительно, увеличить вклад туризма в ВВП и, таким образом, повысить уровень жизни граждан. Возникают следующие вопросы: почему какие-то страны притягивают большее количество туристов, и туризм в значительной степени определяет статус и уровень этих стран, в то время как в иных странах туризм уходит на второй план, и люди даже не рассматривают данную территорию как потенциальное место отдыха. Почему, например, в Россию, являющейся крупнейшей 
страной мира, касаемо территории, обладающей огромным разнообразием флоры и фауны, множеством интересных мест и достопримечательностей, отказываются ехать иностранцы и предпочитают другие страны?

Рассматривая самые популярные туристические направления, в лидерах всегда оказываются такие страны как Франция, Китай, США, Испания, Италия, Турция и Великобритания [9], у которых разный климат и разные притягательные особенности. Данная работа нацелена на поиск зависимостей между притягательностью стран и уровнем их развития. Гипотеза заключается в том, что наиболее популярные туристические страны - это высокоразвитые страны с высоким уровнем экономической свободы. Такие страны вкладывают большие суммы в свое развитие, а значит, капиталовложения в туризм тоже должны быть высокими. Следующая гипотеза - это то, что люди едут в страны, где им интересны достопримечательности, о которых, в первую очередь, можно узнать через Интернет. Значит, необходимо провести исследование зависимости поиска достопримечательностей в Интернете и непосредственным количеством иностранных туристов в данной стране. По результатам проведённого анализа, сравнив 12 стран в период с 2008 по 2018 года (данный промежуток был выбран, чтобы избежать искажения данных из-за распространения коронавирусной инфекции), получились следующие выводы. Т-критерий показал, что между разными, случайно выбранными странами есть различия, так как $\mathrm{t}$ фактический больше $\mathrm{t}$ табличного. F-критерий не везде получился больше табличного. Это означает, что эти страны не всегда различаются между собой, так как их вариация и разнообразие могут быть одинаковы. Однако многофакторный дисперсионный анализ показал, что зависимость турпотока от принадлежности к стране выше, чем от показателя года.

Для доказательства, что развитие экономики оказывает воздействие на развитие туризма, были рассмотрены 2 индекса: индекс процветания страны и индекс экономической свободы. Индекс процветания страны содержит в себе 8 суб-индексов - это экономика, предпринимательство и возможности, управление, образование, здоровье, безопасность, личная свобода и социальный капитал. Если подтвердится влияние этих индексов на туризм, то это докажет гипотезу о том, что людям интереснее ездить в высокоразвитые страны, потому что высокий уровень жизни и экономическая свобода привлекает иностранцев, или, как минимум, создает условия для развития самого туризма.

Целью данного исследования является идентификация системной зависимости между переменными и формулирование решения по увеличению привлекательности туризма в контексте экономического развития для разных стран с учетом их особенностей. Некоторым странам это необходимо для увеличения притока денежных средств в страну и поднятия уровня ее значимости.

В последние годы, несмотря на то что из-за пандемии туристическая отрасль сильно пострадала, интерес к туризму неуклонно растет. Однако мало кто исследует влияние инноваций на туризм. Обзор литературы показал низкий уровень информации в исследовании этой тематики. Исследования взаимосвязи экономки и туризма показывают, что динамическое поведение туризма и экономического роста неоднородно. Это, в основном, связывают с анализом сложности и нелинейными моделями [3]. Однако многие исследователи сходятся на том, что зависимость есть, хотя и не во всех странах она является заметной. Также подчеркивается, что доказательства в пользу зависимости темпов роста могут оправдать масштабы государственной политики в отношении индустрии туризма [6]. Таким образом, было выявлено, что в некоторых странах имеется зависимость между туризмом и экономикой страны, но оказалось, что не все страны подвержены такому влиянию. В данном случае это можно объяснить тем, что в этих странах либо плохо развит туризм, либо же страны развиваются и увеличивают свой ВНД за счет других отраслей и другого влияния, что, в свою очередь, не опровергает теорию о важности развития туризма и его влияния на экономику. Очевидно, что развитие туризма должно провоцировать экономическое развитие, так как создаются дополнительные рабочие места, поощряется развитие культуры, образования, отдыха и бизнеса, а также стимулируется развития инфраструктуры.

Для развития и успешного функционирования рынка услуг туризма необходимы значимое материально-техническое и финансовое обеспечение, расширение разнообразия туристских продуктов, постоянное стремление к улучшению качества туристских продуктов, повышение 
рентабельности функционирования в «мертвые» сезоны, эффективное использование туристскорекреационной инфраструктуры, постоянная адаптация предложения к изменениям вкусов туристов и развитие креативной рекламы [14]. В статье «Global tourism vulnerability to climate change» был сделан вывод, что изменения климата оказывает свое воздействие и должно быть учтено в планах развития туризма [7].

Существуют разные точки зрения по поводу инвестиций в туризм. Исследование Alama Md.-S. Paramati S.-R. показало, что инвестиции в туризм положительно влияют на его рост и даже улучшают качество окружающей среды за счет сокращения выбросов СО2 [2]. Однако, в работе A. Sokhanvar были оговорки, что такой принцип работает далеко не везде. Прямые иностранные инвестиции (ПИИ) оказывают негативное влияние на экономический рост некоторых стран и удивительно стимулируют туристическую индустрию в других странах [1]. Гипотеза данной работы заключается в том, что высокоразвитые страны с высоким уровнем экономической свободы влияют на популярность туристических стран. Статьи о влиянии инноваций на развитие туризма помогают осознать, что эта связь существует, и она априори логична. Например, научно-технический прогресс привел к развитию авиационных перевозок, к установлению правовых международных норм [20]. Именно благодаря технологиям и инновациям туризм приобрел современную форму.

Относительно поиска достопримечательностей в Интернете и туризма, Мышлявцевой С.Э. и Ланиным В.В. было проведено исследование, доказывающее важность этих запросов. Представленное исследование было проведено с помощью сервиса «Яндекс.Вордстат» и Python, где изучались достопримечательности Пермского края и их популярность [17]. Существует точка зрения, что социальное влияние с каждым годом оказывает все большее значение на выбор стра- ны туристами. В одной статье «Вестника ATOP» было выявлено, что люди зачастую основывают свой выбор на рекомендациях travel-блогеров и ярких и красивых фотографиях в социальных сетях [12]. Таким образом, был сделан вывод о рациональности выдвинутых гипотез. Противоречивость требует более тщательного изучения, а отсутствие некоторых исследований в данной области показывает уникальность данной работы. Уже сейчас, на основе литературного обзора, можно предположить, что для развития туризма необходимо постоянное стремление к улучшению, а также его поддержание на высоком уровне. Для описания методологии были использованы показатели, представленные в таблице 1 .

X4 был определен с помощью сервиса Google Trends, в котором анализировался уровень популярности запроса за каждый изучаемый год. Анализ проводился по всему миру и для более объективного результата использовалось 2 запроса "Tourist attractions in (country)" и “Attractions in (country)", после чего было найдено среднее этих значений по каждой стране. Так как уровень популярности запроса находится как относительная величина к самому высокому показателю, то было принято решение, взять за основу запросы достопримечательностей Италии, потому что в большинстве случаев наибольший уровень популярности запросов достигался именно в этой стране. Выдвигается предположение, что на зависимую Ү влияют все независимые X, которые были представлены. Сам Y (приток туристов) влияет на X3 (капиталовложения в туризм) с небольшим временным лагом. То есть, чем больше туристов приезжает в страну, тем больше денег они там оставляют, а соответственно, у государства появляется больший стимул развивать туризм в своей стране. Другая гипотеза состоит в том, что существует связь между X3 (капиталовложениями) и X4 (поиском достопримечательностей в Google). Чем больше денег государство тратит на развитие

Таблица 1. Сводная таблица показателей

\begin{tabular}{|c|l|l|c|}
\hline $\begin{array}{c}\text { Условное } \\
\text { обозна- } \\
\text { чение }\end{array}$ & Наименование показателя и единицы измерения & Тип & Источники \\
\hline $\mathrm{Y}$ & Количество туристов, человек & Эндогенно-экзогенный & {$[16]$} \\
\hline $\mathrm{X} 1$ & Индекс экономической свободы & Экзогенный & {$[16]$} \\
\hline $\mathrm{X} 2$ & Индекс процветания & Эндогенно-экзогенный & {$[16]$} \\
\hline $\mathrm{X} 3$ & Капиталовложения, млрд. долл. США & Эндогенно-экзогенный & {$[16]$} \\
\hline $\mathrm{X} 4$ & $\begin{array}{l}\text { Поиск в Интернете достопримечательностей, } \\
\text { средний уровень }\end{array}$ & Эндогенно-экзогенный & {$[5]$} \\
\hline
\end{tabular}


туризма, тем больше нововведений появляется в стране, что вызывает у людей больший интерес, а следовательно, увеличивается количество поисков в Интернете, в том числе количество поисков новых достопримечательностей. Следующая гипотеза предполагает, что X1 (индекс экономической свободы) влияет на Х2 (индекс процветания), так как граждане страны, где экономическая свобода выше, склонны больше развиваться, проявлять себя и тем самым способствовать развитию страны. Еще одна связь, которую можно предположить на основе этой модели заключается в том, что X3 (капиталовложения в туризм) влияет на X2 (индекс процветания), но через Y (количество туристов), тем самым происходит многоуровневое влияние. То есть, чем больше совершается инвестиций в туризм, тем больше туристов, которые, в свою очередь, оставляют больше денег в стране. Государство, имеющее большее поступление, имеет и больше возможностей вкладываться. И, скорее всего, оно будет больше вкладываться не только в эту отрасль, но и во все остальные, тем самым способствуя развитию и совершенствованию страны. На рисунке 1 представлена получившаяся концептуальная модель.

Для изучения модели использовались данные, которые распределены пространственно по 12 странам (Франция, США, Испания, Италия, Турция, Россия, Китай, Черногория, ОАЭ, Япония, Великобритания и Германия). Чтобы проверить работу модели в разных условиях, были взяты страны, где туризм является определяющим и где существуют другие, более значимые для страны отрасли и пути развития. Анализ произ- водится за период 2009-2018 гг., чтобы избежать влияния пандемии на результаты исследования и проверить модель без учета ограничительных мер, введенных из-за распространения коронавирусной инфекции. В зависимости между экономической свободой и уровнем процветания страны был учтен еще и 2019 год.

Ограничением данного исследования является ограниченность выборки по странам. Следует понимать, что, взяв в рассмотрение другие страны или расширив выборку, результаты могут получиться как более объективными, так и более специфичными, в зависимости от особенностей выбранных стран. Также исследование может быть точнее, если бы была возможность собрать данные запросов не в относительных уровнях, как это можно сделать в Google Trends, а в физических показателях (количествах запросов).

Множественная регрессия проводится панельными данными с целью увеличения наблюдений, чтобы была возможность проверить все переменные, а также для того, чтобы посмотреть работу данной модели в динамике. Протестировав линии тренда независимых переменных, было выявлено, что для X1 и Х2 больше всего подходит полином третей степени, что, скорее всего, связано со спецификами разных стран, находящихся на разных этапах развития, а для X3 и X4 - степенная функция. Исследование проводится с помощью инструментов MS Excel и IBM SPSS, так как это типовые инструменты для статистических исследований. Уровень доверия модели устанавливается на уровне 90\%, то есть, если p-level фактора больше 10\%, он

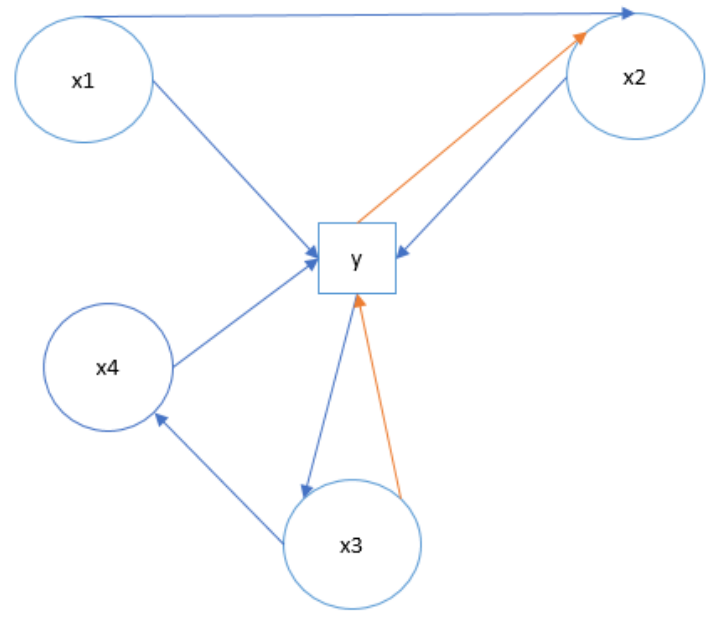

Рисунок 1. Первоначальная концептуальная модель 
исключается из рассмотрения. Пограничное значение фактора инфляции дисперсии (VIF) во избежание мультиколлинеарности (корреляционной связи между объясняющими переменными) устанавливается на уровне 5. Неоптимизированные формы уравнения представлены за 2011-2012 гг.:

$$
\begin{aligned}
& y=345941339,6+94371002,2 x_{1}-1405210,1 x_{1}^{2} \\
& +6802,5 x_{1}^{3}-107915123,3 x_{2}+1605127,3 x_{2}^{2}-7933,1 x_{2}^{3} \\
& +248160 x_{3}+(1,52 E-52) \exp \left(x_{3}\right)+1339579,8 x_{4} \\
& -(4,9 E-17) \exp \left(x_{4}\right) \\
& x_{3}=1,1+(9,06 E-O 7) y \\
& x_{4}=23+0,17 x_{3}-(1,4 E-58) \exp \left(x_{3}\right) \\
& x_{2}=69-1,72 x_{1}+0,04 x_{1}^{2}-0,00018 x_{1}^{3} \\
& y=22840133,28+427788,6 x_{3}-(3,52 E-52) \exp \left(x_{3}\right) \\
& x_{2}=68,78+(8 E-08) y
\end{aligned}
$$

Первичный анализ показывает следующие результаты:

1. По множественной регрессии. Для X3 и X4 был взят временной лаг в 1 год, то есть необходим 1 год для того, чтобы капиталовложения и популярность запросов достопримечательностей в Интернете стали оказывать свое воздействие на количество туристов. После оптимизации модели методом “Назад”, было решено отказаться от всех производных х-ов и от X1 (индекса экономической свободы), так как переменные оказывали на модель линейное влияние, а производные от них лишь препятствовали логическому объяснению и ухудшали модель. Отказ от индекса экономической свободы привел к выводу о том, что туристам не так важен политический режим страны. Вероятно, что туристы даже готовы посмотреть жизнь при разных уровнях экономической свободы. Также был сделан вывод о том, что взятые для исследования страны, в большинстве своем, имеют практически одинаковый уровень индекса экономической свободы. Возможно, если бы для исследования были взяты, например, страны Африки, данный фактор мог бы остаться в модели как значимый. В данной модели были исключены из рассмотрения Италия и Черногория, так как на них представленные показатели действовали в меньшей степени, и эти страны лишь ухудшали модель. Независимые переменные не определяли специфики этих стран. В Италии наибольший интерес у туристов вызывают исторические памят- ники и достопримечательности, произведения искусства и художественные ценности. Также туристов привлекают отдых на море, озёрах и на горнолыжных курортах [8]. Получается, что Италия у людей ассоциируется с туризмом уже давно, данная страна привлекает людей не новыми технологиями и инноватикой, а историческими достопримечательностями. Для Черногории туризм определяется в большей степени снятием жилья, а также там, как и в Италии делается упор на культурные и исторические ценности [19].

2. Исследование модели влияния турпотока на капиталовложения в туризм показало, что количество иностранных туристов оказывало свое воздействие на инвестиции до 2014 года. Причем это влияние осуществлял 2008 год. Это можно связать с экономическим кризисом в 2009 году, после которого люди стали меньше тратить денег на отдых и путешествия, а также со вспышкой Мексиканского гриппа (H1N1) в 2009 г., который затронул 74 страны и также уменьшил количество туристов [15]. Возможно, в период после кризиса произошел переломный момент, где государство осознало, что информационная среда уже настолько развилась, что каждая из стран стала ассоциироваться с определенной совокупностью достопримечательностей и условными константами в сознании потенциальных потребителей. После чего был сделан вывод, что дополнительное развитие туризма становится нецелесообразным, так как предельная ценность падает, а дополнительные доходы от туризма расходуются на другие потребности страны.

3. Анализ связи между капиталовложениями и поиском в Интернете достопримечательностей показал, что данная связь отсутствует. Однако заметна тенденция к улучшению, со временем R2 растет, a p-level уменьшается. Можно также предположить, что в некоторых странах завлекающие туристов достопримечательности существуют уже давно. Но, скорее всего, в будущем эта связь появится, так как появляются новые инновационные достопримечательности, а также растет влияние социальных сетей. Таким образом, широкомасштабная реклама новых мест или достопримечательностей через социальные сети может сработать, и люди больше будут интересоваться какой-либо страной.

4. Проведя парную регрессию между индексами экономической свободы и процветанием, была выявлена связь, однако в ходе оптими- 
зации эта связь оказалось линейной. Этот факт объясняет исключение X1 в множественной регрессии, ведь X1 может оказывать многоуровневое влияние на Y через X2.

5. Проверяя гипотезу о том, что капиталовложения влияют на процветание страны через поток туристов, было проведено две парных регрессии. В ходе первой регрессии, где X3 влияет на Y, была выявлена зависимость, которая уже подтвердилась во множественной регрессии. Более того, было замечено, что при учете временного лага в 3 года, модель становится немного качественнее, и, хотя это изменение незначительное, оно может говорить о том, что деньги, вложенные в строительство некоторых объектов, привлекают туристов только через 3 года. Такое возможно, потому что строительство объектов занимает время, особенно если речь идет о масштабных проектах или строительстве, для которых требуется больше времени на реализацию.

Однако связь между количеством туристов и уровнем процветания не подтвердилась. Значит, что турпоток не оказывает значимого воздействия на процветание или, по крайней мере, это происходит не во всех представленных странах. Возможно также, что данная связь проявляется опосредованно, через еще одну переменную, или в каких-то странах увеличиваются вложения, но не на развитие, а на другие нужды страны. Финальные уравнения, которые были получены после оптимизации, представлены ниже. Парная регрессия представлена с 2009 по 2019 гг., а множественная регрессия с учетом временных лагов с 2011-2012 гг.

$$
\begin{aligned}
& y=78602398-1168491,8 x_{1}+291803 x_{2}+1006045 \\
& x_{2}=11,1+0,8728 x_{1} \\
& y=73227982-1073141 x_{1}+265531,6 x_{2}+975787,2 x_{3} \\
& x_{2}=10,77+0,8736 x_{1} \\
& y=88296025-1373243 x_{1}+181941,6 x_{2}+1522459 x_{3} \\
& x_{2}=10,68+0,8813 x_{1} \\
& y=81621993-1155090 x_{1}+156600,3 x_{2}+1182736 x_{3} \\
& x_{2}=12,21+0,8718 x_{1} \\
& y=95849433-1534244 x_{1}+70825,38 x_{2}+1528529 x_{3} \\
& x_{2}=10,28+0,8947 x_{1} \\
& y=88506986-1404714 x_{1}+22443,812 x_{2}+1652754,6 x_{3} \\
& x_{2}=11,7+0,8725 x_{1} \\
& y=100501742,5-1573819,55 x_{1}-1565,2 x_{2}+1744601,8 x_{3} \\
& x_{2}=14,55+0,831 x_{1}
\end{aligned}
$$

В модели множественной регрессии ошибка аппроксимации не превышает 35\%. Данные результаты говорят о том, что к модели нужно относиться осторожно. В какие-то года ошибка меньше 30\%, а значит, среднее отклонение расчетных значений от фактических меньше. Наибольшая ошибка аппроксимации достигается в 2014-2015 гг. Скорее всего, оказала влияние Олимпиада в Сочи (Россия) в 2014 г., а также политический кризис 2013-2014гг, который во3ник из-за присоединения Крыма к России. Пограничное значение VIF было принято на уровне 5, эти требования модель удовлетворяет. VIF1 и VIF2 даже не превышают трех. Однако VIF3 со временем становится больше, значит, у Х4 (поиск в Интернете) появляется некоторая интеркорреляция с остальными переменными. Следовательно, можно предположить, что в будущем, для того чтобы увеличить интерес людей к поиску достопримечательностей в разных странах, необходимо будет больше инвестировать в туризм и развивать страну. Остатки показывают небольшую и приемлемую гомоскедастичность, которая может быть связана с выбросами. Однако, в основном, наблюдается гетероскедастичность. В 2014-2015 гг. остатки распределены гомоскедастично, значит, в эти года заложена информация, которую представленная модель не объясняет. Это может оправдывать предположения, сделанные в анализе ошибки аппроксимации. После 2015 г. наблюдается улучшение, и остатки снова становятся гетероскедастичными, а начиная с 2017 г., остатки приходят в тот вид, который был изначально в 2011-2012 гг., что может указывать на некоторую цикличность развития.

Сопоставляя фактический и теоретический значения в 2011-2012 годах, наблюдаются структурные выбросы. В Испании и Германии они являются незначительными. Однако во Франции и Японии они заметны. Фактический Y во Франции выше верхней границы. В этой стране много туристов, потому что Франция является неким брендом для посещения и схожа в этом смысле с Италией. Туристическая привлекательность страны объясняется значительным числом достопримечательностей, разнообразием пейзажей, богатством исторического и художественного достояния, умеренным климатом, легкостью транспортного доступа, а также надлежащим обслуживанием туристов и транспортной инфраструктурой [10]. В Японии 
фактический Y выходит за пределы нижней границы. Это может быть связано с атомными бомбардировками Хиросимы и Нагасаки еще во время Второй мировой войны и боязнью людей посещать данную страну. Также это может быть обусловлено с процедурой выдачи виз для иностранных граждан, которая была значительно упрощена в 2010-2013 гг. [13].

В 2017-2018 гг. модель оптимизируется, и структурные выбросы практически полностью уходят, остаются лишь незначительные выбросы (рисунок 2), а значит, данной моделью можно пользоваться, однако следует помнить, что в модели имеется тенденция к увеличению ошибки аппроксимации, поэтому границы расширяются, и фактический Ү за счет этого сглаживается.

После нахождения коэффициента эластичности было выявлено, что управлять можно всеми представленными данными, так как нижняя и верхняя границы каждого фактора находятся в одной плоскости. Не подтвердилась гипотеза, касающаяся индекса процветания, так как коэффициент регрессии и коэффициент эластичности показывают, что между X2 и Ү существует обратная связь. Можно сделать вывод, что данный фактор носит дуалистический характер. С одной стороны, процветающая страна привлекает больше туристов, но с другой стороны, туризм в ней становится дороже, а следовательно, не все люди могут себе такое позволить, и со временем турпоток уменьшается.

Следующий вывод, который можно сделать из анализа коэффициента эластичности - это то, что безопаснее всего управлять X2 (капиталовложениями), так как диапазон этого фактора между нижней и верхней границей наименьший.
Получается, что при увеличении инвестиций в туризм на $1 \%$, количество туристов увеличится с 0,19 до 0,37 процентов. Однако наиболее результативный эффект будет давать увеличение поисковых запросов достопримечательностей страны в Google, так как пик приходится именно на эту переменную. Начиная с 2015 года X2 начинает работать непредсказуемо, так как нижняя граница для этого фактора становится отрицательной, а верхняя остается положительной, промежуток между значениями попадает в 0 (рисунок 3), однако нельзя сказать, что моделью пользоваться нецелесообразно, так как по графику видно, что отрицательные последствия очень маловероятны.

По результатам проведения множественной регрессии и выявлении коэффициента детерминации, видно, что модель является актуальной. И хотя со временем, она немного ухудшается, ею можно пользоваться, можно опираться на сделанные выводы для дальнейшего изучения и нахождения новых независимых переменных. Также можно сделать предположение, что модель циклична и, возможно, через несколько лет (учитывая распространение пандемии) коэффициент детерминации станет даже выше.

В парной регрессии также была выявлена линейная зависимость. Экономическая свобода определяет процветание страны. И хотя коэффициент детерминации не такой высокий, как в предыдущей модели (до 2016 года он больше $60 \%$, а затем колеблется на уровне $45 \%$ ), все же индекс свободы определяет значительную часть индекса процветания. Со временем эта связь немного ухудшается, возможно, появляются новые факторы, которые начинают оказывать большее

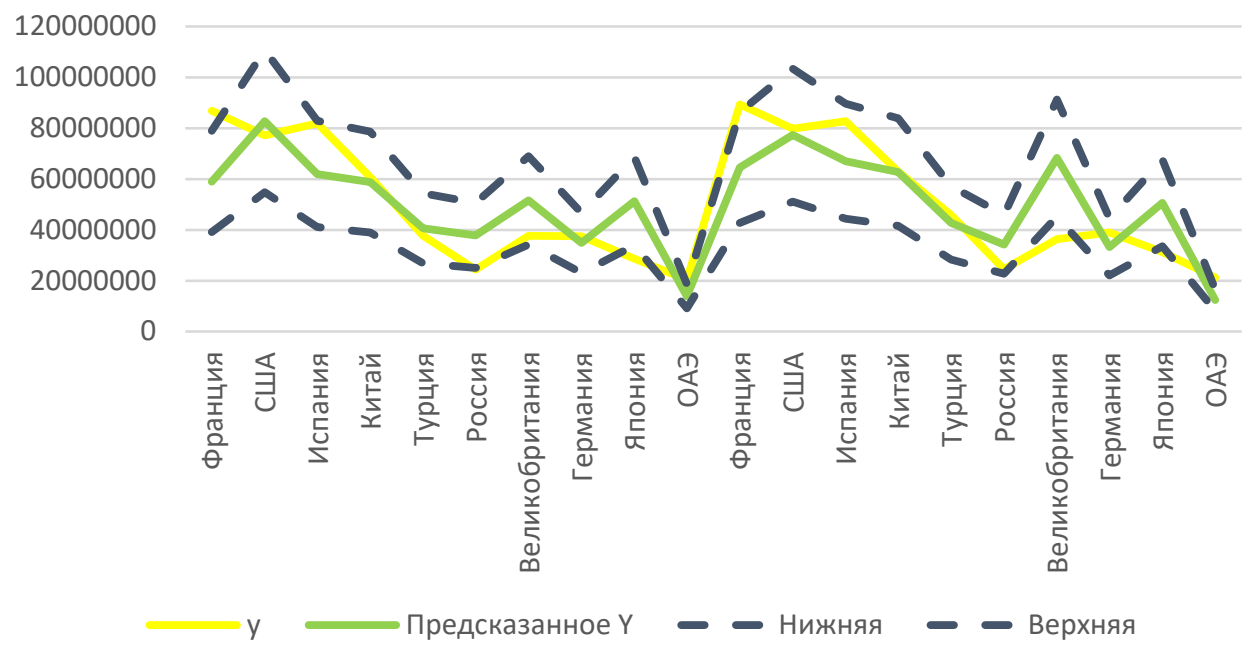

Рисунок 2. Сопоставление фактического и теоретического значений в 2017-2018 гг. 


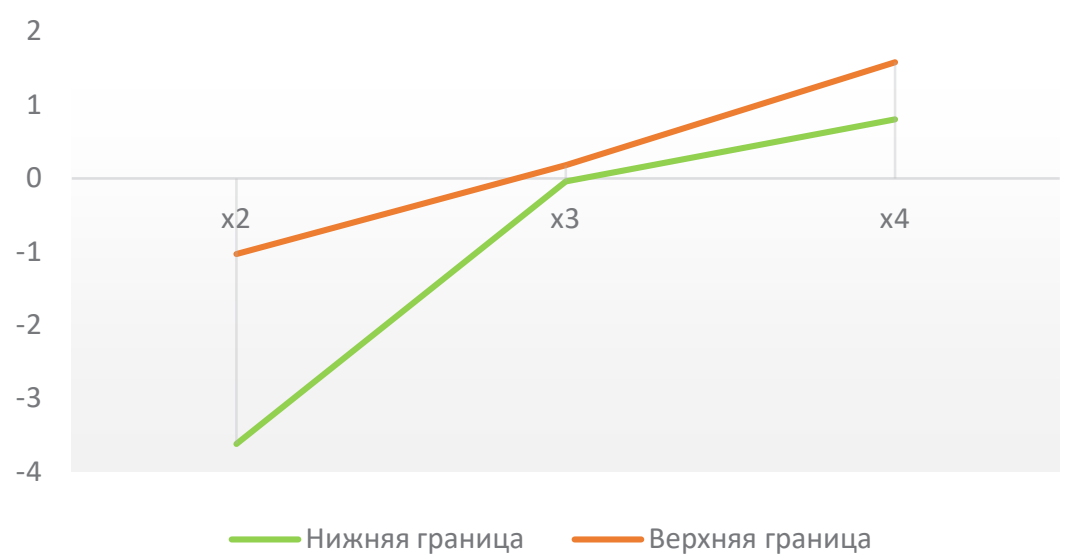

Рисунок 3. Границы коэффициента эластичности в 2015-2016 гг.

воздействие на индекс процветания (например, политическая свобода или влияние виртуального рынка), тем самым снижая влияние индекса экономической свободы.

Полученным результатам по парной регрессии можно доверять на 95\%, а ошибка аппроксимации почти везде оказалась меньше $10 \%$, что указывает на высокую достоверность модели. Начиная с 2017 года ошибка аппроксимации немного увеличивается, что может подтверждать гипотезу, что процветание страны и ее экономика стали зависеть от новой переменной, например, от влияния виртуального рынка, поскольку как раз в это время начали широко распространяться криптовалюты. Остатки парной регрессии показывают гетероскедостичность и несколько небольших выбросов, что еще раз подтверждает, что модель значимая и ею можно пользоваться. Сопоставление теоретического и фактического значений и допустимых границ представлены на рисунке 4. Наблюдаются небольшие структурные выбросы во Франции и в
Германии, которыми можно пренебречь. А также выделяется более значимый выброс в Турции, причем в данном случае фактический Ү выходит за рамки нижней границы. Скорее всего, постоянные конфликты между соседними странами сдерживают развитие данной страны [11].

Коэффициент эластичности парной регрессии показывает, что при увеличении индекса экономической свободы на $1 \%$, индекс процветания увеличивается с 0,49 до 1,18 процентов, а значит, этой связью можно управлять. Со временем границы данного коэффициента растягиваются. В 2019 г. при увеличении индекса экономической свободы на 1\%, индекс процветания увеличивается с 0,21 до 1,31 процентов. Получается, что, управляя индексом экономической свободы, есть возможность в большей степени изменить индекс процветания. По результатам исследования фактическая (подтвержденная) модель получилось усеченной и представлена на рисунке 5.

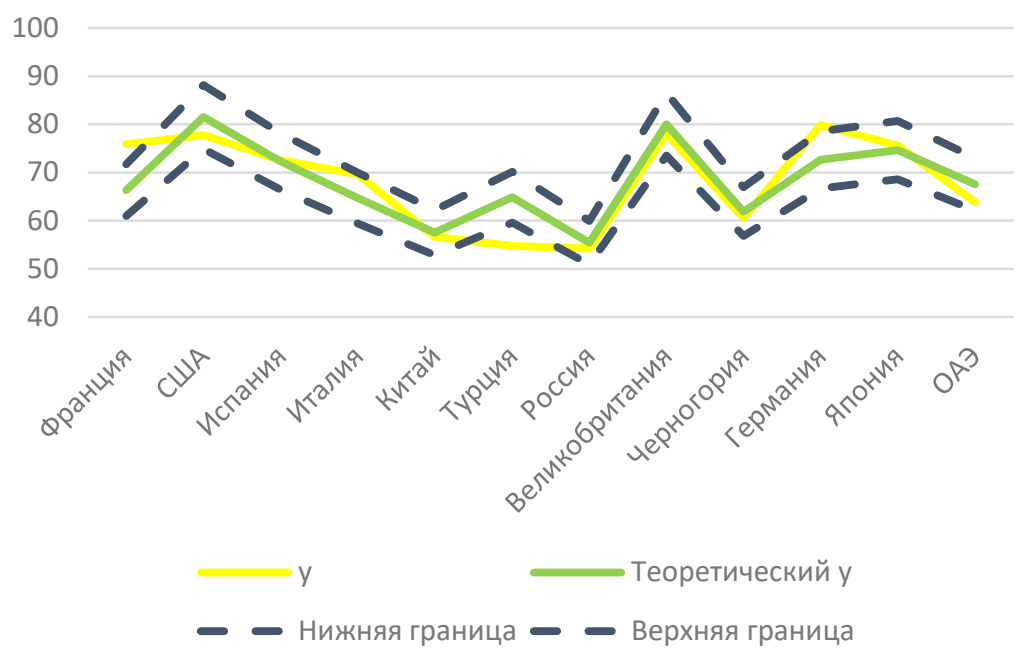

Рисунок 4. Сопоставление фактического и теоретического Ү в парной регрессии в 2009 г. 


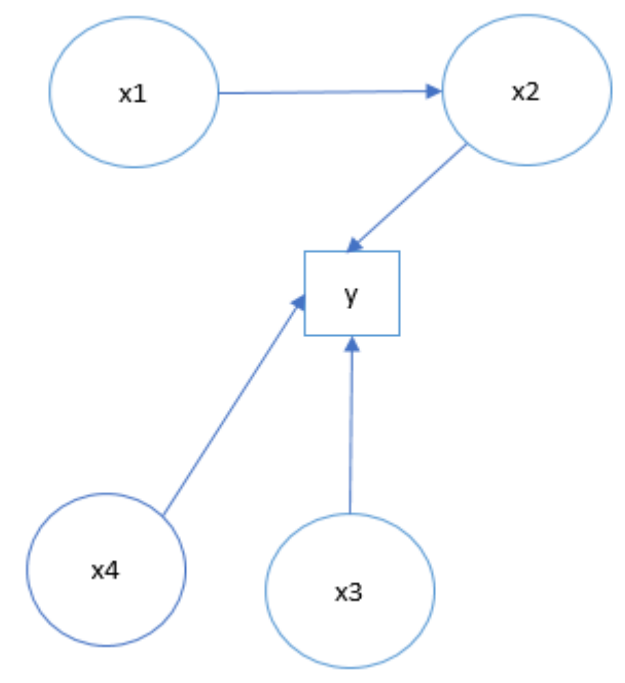

Рисунок 5. Фактическая подтвержденная модель

Подводя итоги, можно сделать вывод, что модель предоставляет значимые результаты, на основе которых можно формировать стратегию управления туризмом, а также проводить дальнейшие исследования в данной области.

В данной работе было доказано, что турпоток оказывает значимое влияние на экономику страны и на ее развитие в целом. Это влияние неоднородно, и в каждой стране есть своя специфика, поэтому подход к каждой стране должен быть уникальным, необходимо проводить метаанализ и изучать особенности.

Вывод о том, что существует множество переменных, влияющих на турпоток, тоже подтверждается. Во-первых, это показывает коэффициент детерминации, который хотя и остается на высоком уровне, но все равно указывает на то, что есть другая компонента, которая описывает оставшуюся долю вариации результативного признака. Во-вторых, в ходе проведения исследования, были исключены некоторые страны, которые описываются другими переменными. И, в-третьих, в некоторые года возрастала ошибка аппроксимации или были фактические выбросы по странам, которые объяснялись метастатистикой, а соответственно, другой/другими переменными.

Информация о капиталовложениях в туризм тоже совпала с уже сделанными выводами в литературном обзоре. В основном, капиталовложения в туризм положительно влияют на приток туристов, но с 2015 г. нижняя граница коэффициента эластичности лежит ниже нуля, а значит, управляя этой переменной, можно по- лучить отрицательный результат. Скорее всего, это возможно, когда речь идет об иностранных инвестициях, то есть о деньгах из другой страны. Если окажется, что вкладываемые инвестиции превышают доходы данной страны, то это приведет к инфляции. И, так как продукты станут дороже, а население беднее, то через какое-то время туристы могут потерять интерес к данной стране, ведь страна перестанет процветать и вкладываться в новые разработки или проекты [18]. Существует также предположение, что высокие инвестиции приведут к увеличению турпотока, что, в свою очередь, может способствовать экологическим или социальным проблемам, которые в конечном счете, через определенный промежуток времени, приведут к уменьшению турпотока. Таким образом, капиталовложения в туризм положительно влияют на приток туристов. И хотя возможен исход, что капиталовложения будут оказывать отрицательное воздействие, это, скорее, является исключением, и вероятность этого крайне мала.

Исследования о взаимосвязи инноваций и туризма показало, что в высокоразвитых странах, действительно, турпоток выше, чем в остальных странах. Но дело здесь, главным образом, не в том, что люди хотят посмотреть на научные разработки и на жизнь в развитой стране, а в том, что в эти страны легче всего попасть. Например, в 2011-2012 гг. наблюдается большой выброс фактического Ү (турпотока) во Франции, что можно объяснить тем, что французские города имеют международные аэропорты, которые связывают Францию почти со всеми стра- 
нами мира, а также Франция имеет вторую по величине железнодорожную сеть Европы общей протяженностью 29901 км. [4]. То есть, возможно даже, что некоторые туристы Франции вынуждены быть таковыми, потому что их путь лежит через эту страну, и они не могут по-другому доехать до назначенного пункта.

Поиск достопримечательностей в Интернете тоже подтвердил свое влияние на количество туристов. Исследование показало, что Интернет имеет все большее значение не только для турпотока, но и для инфраструктуры в целом. Связь между капиталовложениями в туризм и поиском достопримечательностей хотя и не подтвердилась, но с каждым годом становилась все лучше, а значит, в будущем, вполне вероятно, что она появится.

Следовательно, можно оказывать влияние на количество туристов, однако для каждой страны требуется индивидуальный подход, потому что необходимо учитывать множество факторов и специфик. Проверка гипотез показала, что на турпоток оказывают такие переменные, как индекс процветания страны, капиталовложения в туризм, поиск в Интернете достопримечательностей и индекс экономической свободы, который имеет многоуровневое влияние и оказывает свое воздействие через индекс процветания. Получается, влияя на данные переменные, можно влиять на количество иностранных туристов.

Дуалистический характер носит индекс процветания. Данный индекс непосредственно определяет стоимость жизни, и, как правило, чем он выше, тем становится дороже пребывать в стране. У жителей развитых стран наблюдается высокая заработная плата, они могут себе позволить такую жизнь, но далеко не все туристы имеют такую возможность. Однако это работает не всегда так, например, уровень процветания России относительно невысокий, но отдыхать в России затратно. В первую очередь, в России высокие цены на транспорт. Это может быть связно с тем, что на данном рынке практически отсутствует конкуренция. Такие компании как “РЖД”, “Аэрофлот” являются доминирующими и зачастую «диктуют» свои цены. Во-вторых, в России, по сравнению, например, с Францией или Италией, нет туристического бренда, компаниям тяжело развиваться и окупать свои затраты, в том числе из-за дорогого транспорта они могут иметь не так много туристов и, чтобы хоть как-то поддерживать свой бизнес, владельцы вынуждены завышать расценки, тем самым сокращая турпоток. Получается, что некая негласная монополия мешает тому, чтобы цены в России в отрасли туризма соответствовали уровню жизни в этой стране. Таким образом, государству стоит обратить на это внимание, можно поставить некоторые ограничения цены на транспорт, бороться с коррупцией, проводить внешний аудит, а также при необходимости поддерживать эту отрасль дотациями при соблюдении требований, которые помогут снизить. Другой вариант решения это предоставить другим компаниям, например, иностранным, возможность для развития своих услуг по перевозке людей, таким образом увеличив конкурентоспособность отрасли.

Относительно остальных исследуемых стран, в которых цены пребывания в стране тем дороже, чем развитее страна, заметна диалектика. Уже было доказано, что развитие страны непосредственно влияет на развитие туризма, но как выяснилось, впоследствии это может оказывать и отрицательное влияние на развитие туризма, в том числе из-за того, что через какой-то период времени большой поток туристов может привести к социальным конфликтам или экологическим проблемам. Получается, что, развивая туризм, можно в то же время мешать развитию туризма. Страны стремятся к повышению индекса процветания, и они могут этого добиться и извлечь для себя выгоду за счет наращивания туризма. Деньги, которые будут извлечены из туризма, могут направиться на улучшение жизни населения, увеличивая тем самым индекс процветания. Страна же по мере этого развития будет также развивать и туристический базис. Таким образом можно прийти к тому, что имеется во Франции, где наблюдается и высокий уровень процветания, и большое количество туристов. Люди продолжают ездить туда, потому что данная страна имеет туристический бренд и развитую туристическую инфраструктуру.

Капиталовложения в туризм влияют на турпоток с временным лагом в 1 год. Изучая эту связь, можно сказать, что, увеличивая инвестиции, страна неизменно привлекаем больше туристов, если эти деньги направлены на реализацию значимых задумок, например, на строительство новых, качественных и интересных достопримечательностей. Начиная с 20152016 гг. результат становится менее предсказуемым, и это наглядно показывает коэффициент эластичности, где нижняя граница, начиная с 
этих лет, располагается ниже нуля. Это также можно описать диалектической спецификой и сделать вывод, что, неизменно развивая страну и вкладываясь в нее, в конце концов, развивать туризм становится сложнее, а значит, управлять данными факторами необходимо осторожно и последовательно.

Другой вывод, который удалось сделать - это то, что чем больше уровень запросов достопримечательностей, тем больше туристов приезжают в страну. Для данной переменной тоже был взят временной лаг в 1 год, так как это не дает мгновенного результата. Людям нужно время между поиском информацией и принятием решения, на обдумывание. Это также может объясняться финансовой составляющей, так как не все люди могут легко себе позволить путешествие, необходимо какое-то время на накопления. Также следует принимать во внимание сезонность туристических курортов. Таким образом, чтобы увеличить количество туристов в современном мире, необходимы не только ценные капиталовложения, но и действенная реклама. И это может быть как реклама новых достопримечательностей, так и уже имеющихся. Если популярные travel-блогеры будут позитивно отзываться о каком-нибудь объекте, достопримечательности или стране в целом, то люди будут чаще интересоваться этим, а значит, искать это в Интернете, а следовательно, в дальнейшем сами будут становиться туристами данной страны. И, чтобы большее количество блогеров и известных людей приезжало в страну, можно периодически проводить партнерские программы или брать на себя ответственность в организации премий, для чего как раз необходима техническая оснастка и качественное предоставление услуг, то есть необходимо развитие страны.

Следующее предположение логически возникает из предыдущих. При увеличении капиталовложений в туризм увеличивается и количество поисковых запросов достопримечательностей данной страны в Интернете. Проведенное исследование данную связь не подтвердило, однако со временем заметно улучшение. Проверяя данную связь в течение 9 лет (с 2010 по 2018 гг.), наблюдаются признаки того, что связь появляется и становится значимее, так как p-level уменьшается, но еще не достигает приемлемого значения, а коэффициент детерминации растет. Скорее всего, уже в ближайшем будущем данная связь появится, а значит, ею можно будет управлять. Качественные вложения в развитие туризма могут увеличить популярность поисковых запросов достопримечательностей страны, что, в свою очередь, покажет возросший интерес людей к стране. Более того, данный вывод можно также сделать на основе анализа мультиколлинеарности. С каждым годом VIF для X4 неизменно растет, а значит, с каждым годом поиск достопримечательностей в Интернете все больше коррелирует с индексом процветания и капиталовложениями.

Другая связь, которая подтвердилась в исследовании - это связь между индексом экономической свободы и индексом процветания. Чем выше экономическая свобода в стране, тем больше у людей возможностей для развития и реализации своих идей. Получается, для того чтобы увеличить индекс процветания, необходимо предоставить экономическую свободу, которая позволяет людям свободно зарабатывать деньги, вести бизнес и отстаивать свои права, а также при правильном регулировании увеличивать конкуренцию в стране, тем самым повышая качество продукции и восприятие страны на международной арене. Экономическая свобода означает также свободу международной торговли, а значит, в этих странах находятся международные корпорации, которые позволяют увеличивать деловой туризм. Более того, развитые страны заманивают больше профессионалов, и происходит “утечка мозгов” из других стран. Получается, что индекс экономической свободы тоже влияет на турпоток, но это влияние многоуровневое, через индекс процветания. Таким образом, чтобы увеличить количество иностранных туристов, стране необходимо поддерживать высокий уровень экономической свободы, предоставляя гражданам больше прав, возможностей, а также поддерживая малый бизнес, увеличивая тем самым конкуренцию и развивая экономику.

Гипотеза о влиянии капиталовложения на количество туристов подтвердилась не в полной мере. Капиталовложения 2008 г. оказывали влияние на турпоток вплоть до 2014 г., после чего эта связь пропала. В 2009-2014 гг. информационная среда уже могла развиться настолько, что каждая из стран, как бы она не вкладывалась в туризм, продолжала восприниматься туристами относительно константно. И страны, соответственно, тоже продолжали развиваться относительно константно, соответствуя своему темпу. 
Возможно, что развитым странам с высокой долей туризма это дополнительное вложение уже и не нужно, так как предельная полезность от вложений будет уменьшаться. Но странам, у которых не такой высокий турпоток, следует обратить на это внимание. Чтобы переломить эту константность, необходимо трансформировать положение страны в информационной среде, это также можно сделать посредством привлечения СМИ, журналистов и блогеров.

Зависимость индекса процветания от количества туристов не была обнаружена. Значит, деньги, которые получает государство от иностранных туристов, не вкладываются в экономику, образование, здравоохранение и другие составляющие этого индекса в полной мере. Также, как уже было выяснено, эти деньги не идут на развитие самого туризма. Значит, возникает предположение, что деньги расходуются на удовлетворение каких-то других потребностей страны. Из этого можно сделать вывод, что некоторые страны, которые развивают туризм и имеют большое количество туристов, могут наносить ущерб другим отраслям, не развивая их. Например, страна может не уделить должного внимания промышленности или сельскому хозяйству, и, чтобы восполнить данный дисбаланс, государству приходится направлять большую часть денег на приобретение продукции, которой не хватает. Особенно это невыгодно странам, которые не состоят в каких-либо союзах, потому что в таком случае государству приходится уплачивать таможенные и акцизные пошлины по полной стоимости, без льгот. Чтобы избежать такого неравновесия в преобладании одной отрасли, необходимо способствовать диверсифицированному развитию. Важно объединять усилия разных стран на создание максимально качественного продукта с минимальными затратами, а также иметь некую “подушку безопасности”, и во избежание полной зависимости от другой страны, акцентировать свое внимание не только на одну область. Получается, что развитие туризма должно происходить в концепции всего развития страны.

Таким образом, можно сделать вывод, что на поведение людей и на их выбор влияет множество факторов, поэтому нет универсальной схемы и стратегии для увеличения турпотока. Мир многообразен и неустойчив, и, чтобы качественно чем-то управлять, необходимо непосредственно находиться в данной среде, учитывать разнообразные факторы и всевозможные исходы. Общий вывод заключается в том, что развитие туризма носит системный характер. Развивая его, необходимо развивать государство в целом. При этом важно все делать поступательно, не максимизируя потенциальную прибыль, а оптимизируя ее, учитывая всю специфику и даже двунаправленное влияние результата.

\section{Библиографический список}

1. A. Sokhanvar Does foreign direct investment accelerate tourism and economic growth within Europe? [Статья].2018 г..

2. Alama Md.-S. Paramati S.-R. The dynamic role of tourism investment on tourism development and CO2 emissions [Статья].- 2017 г..

3. Bridaa J.-G. Gómez D.-M., Segarraa V. On the empirical relationship between tourism and economic growth [Статья].- 2020 г..

4. FB [В Интернете] // Транспорт Франции: виды, развитие.-15 декабрь 2020 г.. - https://fb.ru/article/353914/ transport-frantsii-vidyi-razvitie.

5. Google Trends.

6. Pérez-Rodrígueza J.-V.Ledesma-Rodríguez F., Santana-Gallego M. Testing dependence between GDP and tourism's growth rates [Статья]. - 2013-2014 г..

7. Scott D. Hall C. - M., Gösslingbe S. Global tourism vulnerability to climate change [Статья]. - 2018 г..

8. VISIT PLUS [B Интернете] // Италия - статистика туризма. - 25 ноябрь 2020 г..- http://www.visit-plus.com/ ru/node/3603.

9. Wikipedia [В Интернете] // Туризм во Франции.- 14 декабрь 2020 г..- https://ru.wikipedia.org/wiki/\%D0\%A2 \%D1\%83\%D1\%80\%D0\%B8\%D0\%B7\%D0\%BC_\%D0\%B2\%D0\%BE_\%D0\%A4\%D1\%80\%D0\%B0\%D0\%BD\%D1\%86\% D0\%B8\%D0\%B8.

10. Wikipedia [В Интернете] // Список стран по туристическим посещениям.- 12 октябрь 2020 г..- https:// ru.wikipedia.org/wiki/Список_стран_по_туристическим_посещениям\#Азия_и_Океания.

11. Андросова Ю cyberleninka [В Интернете] // Геополитическая стратегия Турции в XXI в. - 14 декабрь 2020 г..https://cyberleninka.ru/article/n/geopoliticheskaya-strategiya-turtsii-v-xxi-v. 
12. Вестник АТОР [В Интернете] // Как соцсети влияют на выбор туристов. - 2016 г..- ноябрь 2020 г.. - https:// www.atorus.ru/news/press-centre/new/34889.html.

13. Г.Б. Бессонова cyberleninka [В Интернете] // Развитие международного туризма в Японии. -14 декабрь 2020 г.. - https://cyberleninka.ru/article/n/razvitie-mezhdunarodnogo-turizma-v-yaponii.

14. Е.Н. Валединская Роль и значение стратегического развития сферы услуг туризма и гостеприимства в региональной экономике [Журнал] // Современные проблемы сервиса и туризма. -2012 г..

15. Итоги 2009 года. | Туризм, путешествия, отдых за границей.

16. Мировая и региональная статистика, национальные данные, карты и рейтинги.

17. Мышлявщева С. Э., Ланин В.В. Подходы к изучению пользовательского интереса к туристским достопримечательностям (на основе анализа поисковых запросов пользователей в сети Интернет) [Журнал] // География и туризм. -2018 г..

18. Туризм | Положительные и отрицательные аспекты туристской деятельности.

19. Черногория: туризм, отели, достопримечательности, кухня, религия, пляжи, лечебный отдых, виза, прокат авто = Особенности туризма в Черногории.

20. Ю.М. Горенбургов О возрастающей роли использования Интернет-технологий в организации туризма [Журнал] // Вестник национальной академии туризма. -2007 г.. 